\title{
Emergency neurosurgery for traumatic brain injury: the need for a national and international registry study
}

\author{
(DDavi J. Fontoura Solla ${ }^{1}$ \\ DDanilo Gomes Quadros ${ }^{1}$ \\ (iD) Angelos G. Kolias 2,3 \\ (iD David J. Clark 2,3,4 \\ (D) Peter J. Hutchinson ${ }^{2,3}$ \\ (D) Manoel Jacobsen Teixeira ${ }^{1}$ \\ (D) Almir Ferreira de Andrade ${ }^{1}$ \\ (iD) Wellingson Silva Paiva ${ }^{1}$
}

1. Divisão de Neurocirurgia, Departamento de Neurologia, Hospital das Clínicas da Faculdade de Medicina da Universidade de São Paulo, São Paulo, Brasil 2. Division of Neurosurgery, Department of Clinical Neurosciences, Addenbrookess Hospital and University of Cambridge, Cambridge, UK 3. NIHR Global Health Research Group on Neurotrauma, University of Cambridge, Cambridge, UK 4. Division of Neurosurgery, University Teaching Hospital, Lusaka, Zambia

Traumatic Brain Injury (TBI) continues to be a global public health issue, affecting millions of lives and with an incidence that varies from some tens to many hundreds of cases per 100.000 inhabitants yearly, depending on the country. Its impact, however, is not homogeneous among high and low Human Development Index (HDI) countries, which have faced different recent transformations on TBI epidemiology ${ }^{1}$. Low-income countries, with less resource availability, observe TBI incidence increase partially due to an expansion on the number of motor vehicles. On the other side, populational aging poses new challenges to high-income countries, along with the proportional increment on standing height falls and victims' basal frailty ${ }^{2}$.

Brasil is situated at the upper-middle-income stratum and deals simultaneously with both sides of the aforementioned spectrum of transformations. It is estimated that more than one million Brazilians are victims of TBI annually, of which $20-30 \%$ are classified as moderate or severe ${ }^{3}$. What was once regarded as an epidemic situation, can no longer be classified as such since it is already part of the quotidian of the large metropolis and small towns in Brasil. According to data from the Hospital Information System of the Brazilian Unified Health System Informatics Department (Sistema de Informações Hospitalares do Departamento de Informática do SUS - SIH /DATASUS), there was a more than $10 \%$ increase on the number of hospitalizations due to TBI over the last 10 years - currently, more than 100.000 / year. Despite a sensitive reduction on hospital lethality from 10.5\% to $9.5 \%$ (including any TBI severity), it was observed an increase on the mean length of hospital stay (less 
than 6 days to approximately 6.5 days), as well as on the direct mean cost per hospitalization (40\% higher, totaling around $\mathrm{R} \$ 1750)^{4}$. As all secondary databases, the DATASUS has inherent limitations, particularly underreporting and cost underestimation. Still, there are few studies on this matter at a national level, none with primary data, which seems limited to some investigations on restricted cities or regions ${ }^{\mathbf{5 , 6}}$.

We should recognize that the tendencies above are not homogeneous throughout the Brazilian territory and an even more extreme discrepancy is expected regarding the management of TBI patients and Neurosurgical practice ${ }^{7}$. Although there are some publications on the experience and results of some Neurosurgery services in our country, one should know that these are isolated commendable efforts, and the national neurosurgical prospect and its regional heterogeneities and specificities are unknown. For this specific lack of information, the available secondary databases are even more limited, and the Neurosurgical community responsibility on filling this gap grows.

Considering that these knowledge gaps are also observed in other low-and-middle-income countries, an initiative by the Global Health Research Group on Neurotrauma, funded by the United Kingdom National Institute for Health Research (NIHR) / National Health Service (NHS), was developed: The Global Neurotrauma Outcomes Study (GNOS). It is the first global registry study about the outcomes of patients submitted to emergency neurosurgery for TBI ${ }^{8}$.

This is a prospective, multi-center, international cohort study that aims to provide a comprehensive international picture of the management and outcomes of patients undergoing emergency surgery for TBI worldwide - the first of its kind endorsed by the World Federation of Neurosurgical Societies (WFNS) and all continental neurosurgical societies. It will be possible to describe differences in patient demographics, clinical characteristics, surgical choices, and postoperative care as well as compare the global practice to the currently accepted standards of care for the surgical management of TBI. The typical resources available for essential and emergency neurosurgical care may greatly differ between high and low HDI countries. In addition, this initiative will establish a platform and clinical network to facilitate future research in neurotrauma and neurosurgery.

Any Neurosurgery service that performs emergency surgery for TBI is welcome to collaborate. More information is available at https://globalneurotrauma.com. Let us move forward!

\section{ACKNOWLEDGEMENTS}

The GNOS study is supported by the National Institute for Health Research (NIHR) Global Health Research Group on Neurotrauma. The Group was commissioned by the NIHR using Official Development Assistance funding (project 16/137/105). The views expressed in this manuscript are those of the authors and are not necessarily those of the UK National Health Service, NIHR, or the UK Department of Health.

\section{REFERENCES}

1. Dewan MC, Rattani A, Gupta S, Baticulon RE, Hung YC, Punchak M, et al. Estimating the global incidence of traumatic brain injury. J Neurosurg. 2018:1-18.

2. Roozenbeek B, Maas Al, Menon DK. Changing patterns in the epidemiology of traumatic brain injury. Nat Rev Neurol. 2013;9(4):231-6.

3. Anghinah R, Amorim RLO, Paiva WS, Schmidt MT, lanof JN. Traumatic brain injury pharmacological treatment: recommendations. Arq Neuropsiquiatr. 2018;76(2):100-3.

4. Brasil. Ministério da Saúde [Internet]. Departamento de Informática do SUS - DATASUS. Sistema de Informações Hospitalares - SIH. 2019. [cited 2019 Apr 12]. Available from: www.saude.gov.br/datasus

5. Almeida CE, Sousa Filho JL, Dourado JC, Gontijo PAM, Dellaretti MA,
Costa BS. Traumatic brain injury epidemiology in Brazil. World Neurosurg. 2016;87:540-7.

6. Fernandes RNR, Silva M. Epidemiology of traumatic brain injury in Brazil. Arq Bras Neurocir. 2013;32(3):136-42.

7. Dewan MC, Rattani A, Fieggen G, Arraez MA, Servadei F, Boop FA, et al. Global neurosurgery: the current capacity and deficit in the provision of essential neurosurgical care. Executive Summary of the Global Neurosurgery Initiative at the Program in Global Surgery and Social Change. J Neurosurg. 2018:1-10.

8. Kolias AG, Rubiano AM, Figaji A, Servadei F, Hutchinson PJ. Traumatic brain injury: global collaboration for a global challenge. Lancet Neurol. 2019;18(2):136-7. 